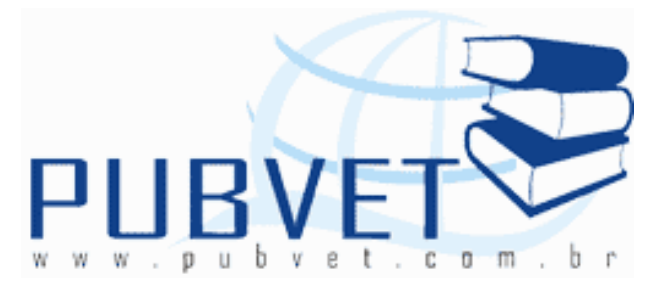

PUBVET, Publicações em Medicina Veterinária e Zootecnia.

\title{
Leguminosas na alimentação de ovinos: possibilidades de uso e resposta animal
}

\section{Thayla Sara Soares Stivari ${ }^{1}$, Alda Lúcia Gomes Monteiro², Edson Ferraz Evaristo de Paula ${ }^{3}$, Sergio Rodrigo Fernandes ${ }^{3}$, Damaris Ferreira de Souza ${ }^{3}$, Susana Gilaverte ${ }^{1}$}

${ }^{1}$ Universidade Federal do Paraná, Programa de Pós-Graduação em Agronomia, Curitiba, Paraná, Brasil.

${ }^{2}$ Universidade Federal do Paraná, Departamento de Zootecnia, Curitiba, Paraná, Brasil.

${ }^{3}$ Universidade Federal do Paraná, Programa de Pós-Graduação em Ciências Veterinárias, Curitiba, Paraná, Brasil.

*E-mail para correspondência: thayla.stivari@gmail.com

\section{Resumo}

No Brasil, a produção animal a pasto é privilegiada pelas extensas áreas de pastagens disponíveis e pelos baixos custos de produção comparada a outros sistemas alimentares. Entretanto, as pastagens nativas com ausência de manejo adequado podem apresentar severas deficiências nutricionais, e as pastagens cultivadas, manejadas erroneamente, tendem à degradação. $\mathrm{O}$ uso de leguminosas forrageiras tem potenciais benefícios ao ambiente pastoril, como incorporação de nitrogênio ao sistema, aumento da capacidade de suporte e qualidade de pastagens quando em consórcio com gramíneas, além 
STIVARI, T.S.S. et al. Leguminosas na alimentação de ovinos: possibilidades de uso e resposta animal. PUBVET, Londrina, V. 5, N. 32, Ed. 179, Art. 1209, 2011.

da melhoria do aporte nutricional aos animais e do desempenho destes. A incorporação de leguminosas nos sistemas de produção de ruminantes pode ser feita sob pastejo direto em consórcio com espécies de gramíneas, na forma de suplementos ou "bancos de proteínas" e, ainda, como suplementação privativa aos animais jovens (creep grazing). O objetivo deste trabalho é discutir as possibilidades de uso de leguminosas forrageiras na produção de ruminantes, com ênfase em ovinos, destacando as principais formas de utilização e os resultados em desempenho animal obtidos na última década.

Palavras-chave: bancos de proteína; consórcio; creep grazing; desempenho animal; suplementação volumosa

\title{
Grazing legumes in sheep nutrition: possibilities of use and animal performance
}

\begin{abstract}
In Brazil livestock production is facilitated by the extensive areas of pasture available and the possibility of lower production costs compared to other feeding systems. However, native pastures with lack of adequate management can show severe nutritional deficiencies and cultivated pastures, managed erroneously, tend to decay. The use of forage legumes has potential benefits to the pastoral environment, such as incorporation of nitrogen to the system, increase on support capacity and quality of pastures intercropped with grasses, as well as improvement of nutrition to animals and these gains in performance. The use of legumes in ruminants production systems can be made, among other ways, under intercropped grazing with grass species, like supplement or protein sources and even as private supplementation to young animals (creep grazing). The objective of this essay is to discuss the potential use of forage legumes in sheep production, especially the main forms of use and results in animal performance during the past decade.
\end{abstract}

Keywords: animal performance; creep grazing; forage supplementation; intercropping; protein sources 
STIVARI, T.S.S. et al. Leguminosas na alimentação de ovinos: possibilidades de uso e resposta animal. PUBVET, Londrina, V. 5, N. 32, Ed. 179, Art. 1209, 2011.

\section{INTRODUÇÃO}

A pecuária de corte brasileira é uma das atividades mais competitivas no cenário mundial. Dispondo de mais de 196 milhões de ha de pastagens nativas e cultivadas (FAO, 2010), a produção animal a pasto no Brasil, quando comparada com outros sistemas alimentares, apresenta-se como forte proposta para a redução no custo de produção. Países como Estados Unidos e Austrália, referências mundiais na produção de bovinos de corte, necessitam, respectivamente, de US $\$ 1,90$ e US $\$ 1,40$ para a produção de um $\mathrm{kg}$ de carne, enquanto no Brasil esse custo é de cerca de US\$0,80 (Agroanalysis, 2008). Apesar dos sistemas em pasto acenarem como vantajosos no cenário internacional, a exploração e o manejo das forrageiras no Brasil ainda é deficitária. Historicamente, a realização de queimadas, a falta de reposição de nutrientes e a não adoção de manejos para conservação do solo levaram a degradação das áreas de pastagens no Brasil, resultando em baixo potencial de utilização das mesmas.

A utilização de pastagens está historicamente relacionada com a produção de ovinos em diversos países. O sucesso de tal prática pode ser observado nos países da Oceania, como por exemplo, a Nova Zelândia, detentora de um rebanho expressivo de aproximadamente 34 milhões de ovinos (FAOSTAT, 2008). A Austrália, por sua vez, ocupa posição de destaque na introdução e melhoramento genético de plantas forrageiras, com programas ativos em leguminosas desde a década de 50 (Hacker, 1997).

No Brasil, a produção de ovinos a pasto tem sofrido modificações ao longo dos anos, deixando de ser realizado com exclusividade em pastagens naturais, e buscando a utilização de pastagens naturais melhoradas (Poli et al., 2009), além de cultivadas e/ou consorciadas.

Boggiano et al. (2006) relataram o melhoramento das pastagens naturais no Uruguai com a introdução de leguminosas (Lotus corniculatus cv. San Gabriel; Lotus pedunculatus cv. Maku; Lotus subiflorus cv. El Rincón; Trifolium repens $\mathrm{cv}$. Zapican), com a aplicação de fósforo e com o manejo cuidadoso que 
STIVARI, T.S.S. et al. Leguminosas na alimentação de ovinos: possibilidades de uso e resposta animal. PUBVET, Londrina, V. 5, N. 32, Ed. 179, Art. 1209, 2011.

o pecuarista realiza nessas áreas, favorecendo as espécies nativas e capitalizando o aumento de fertilidade proporcionado pelas leguminosas.

No Rio Grande do Sul destaca-se o potencial de utilização de pastagens cultivadas de alta qualidade como o azevém anual (Lolium multiflorum Lam.) e a aveia, e a introdução de trevos e cornichão (Lotus spp.) nas pastagens naturais, na produção de bovinos de corte e, mais recentemente, de ovinos (Poli et al., 2009). No Nordeste brasileiro, o enriquecimento do ambiente pastoril por meio da formação de pastagens cultivadas, com participação de leguminosas, tem sido realizado no Semi-Árido e enfatizado pelas instituições de pesquisa (Carvalho Filho et al., 2007).

Nos sistemas de produção de ovinos em pastagens, além da possibilidade de consorciação com gramíneas, as leguminosas podem ser utilizadas como forragens suplementares na forma de banco de proteínas e de forrageira suplementar exclusiva para animais lactentes, prática denominada creep grazing, e de uso pouco freqüente no Brasil. Nesta revisão serão discutidas as possibilidades de uso de leguminosas forrageiras na produção de ovinos, com destaque para as principais formas de utilização e os resultados em resposta animal obtidos na última década.

\section{DESENVOLVIMENTO}

\section{Potencialidades das Leguminosas Forrageiras}

Na década de 60 iniciaram-se os estudos sobre a utilização de leguminosas como alternativa de fornecimento de nitrogênio $(N)$ aos ecossistemas de pastagens localizados em regiões de solos ácidos nos trópicos, nos quais o uso de insumos nitrogenados é baixo (Almeida et al., 2002). O $\mathrm{N}$ pode ser adicionado ao solo por meio das associações simbióticas entre bactérias do gênero Rhizobium e leguminosas (Gonçalves \& Costa, 1994). Portanto, a consorciação entre gramíneas e leguminosas é uma alternativa para suprir a demanda por $\mathrm{N}$ das gramíneas, aumentando a produtividade e a qualidade destas espécies e, por conseqüência, a capacidade de suporte da pastagem. 
STIVARI, T.S.S. et al. Leguminosas na alimentação de ovinos: possibilidades de uso e resposta animal. PUBVET, Londrina, V. 5, N. 32, Ed. 179, Art. 1209, 2011.

Destaca-se que os gastos com fertilizantes nos sistemas intensivos de criação podem representar mais de $60 \%$ do custo de produção (Barcellos et al., 2008).

Dentre as vantagens do uso de leguminosas em pastagens podem ser mencionadas: melhoria dos níveis de proteína e menor variação estacional no valor nutritivo da forragem (Jingura et al., 2001); maior consumo e digestibilidade da forragem; melhor distribuição da produção de forragem na pastagem ao longo do ano; e a melhoria da fertilidade do solo, por meio do aumento dos teores de $\mathrm{N}$ e de minerais (Santos et al., 2002; Barcellos et al., 2008; Carvalho \& Pires, 2008).

Por outro lado, as limitações para o uso de leguminosas estão relacionadas aos baixos níveis de fósforo em solos tropicais, nutriente bastante exigido por estas espécies, e as diferenças fisiológicas entre leguminosas e gramíneas, principalmente entre as taxas de crescimento destas espécies. Ambos os fatores influenciam a produtividade de leguminosas em ambientes tropicais.

O potencial benéfico das leguminosas nos sistemas de produção animal em pastagens é conhecido há muitos anos. Thomas (1995) relatou que as leguminosas forrageiras tropicais podem fixar de 2 a $183 \mathrm{~kg}$ de N/ha/ano, sendo que a fixação biológica de $N$ (FBN), principal via de inclusão do $N$ atmosférico no sistema solo-planta, varia entre 70 e $94 \%$ do $N$ existente na parte aérea. Apesar do grande potencial de fixação, a FBN pode ser afetada pela acidez do solo, salinidade, deficiências ou excesso de minerais, estresse hídrico, variações na temperatura, pela quantidade de $\mathrm{N}$ inorgânico no solo, além de pragas e doenças. Quanto menor for o teor de $\mathrm{N}$ no solo, maior será a proporção de $\mathrm{N}$ da planta derivado da FBN, que pode estar acima de $85 \%$ (Barcellos et al., 2008).

A preocupação recente sobre os efeitos ambientais dos sistemas de produção animal tem exposto outro potencial benéfico das pastagens incrementadas com leguminosas. As leguminosas forrageiras, participando da dieta animal, aportam maior quantidade de nutrientes à dieta e propiciam melhoria de parâmetros ruminais podendo reduzir a metanogênese (Montenegro \& Abarca, 2000). 
STIVARI, T.S.S. et al. Leguminosas na alimentação de ovinos: possibilidades de uso e resposta animal. PUBVET, Londrina, V. 5, N. 32, Ed. 179, Art. 1209, 2011.

Alguns aspectos têm sido enfatizados nessa última década por pesquisadores europeus, compilados por Scollan et al. (2005), com boas perspectivas para uso de leguminosas nas dietas de ruminantes. Estudos foram descritos sobre a utilização de trevo vermelho (Trifolium pratense L.) comparado às gramíneas na forma de silagem, observando-se redução substancial na extensão da biohidrogenação ruminal do ácido linolênico 18:3 n-3. Esse efeito foi relatado como resultante à presença da polifenol oxidase (PPO), que é ativada quando o tecido vegetal do trevo é danificado, reduzindo a extensão da lipólise.

Rutter et al. (2003) observaram que vacas leiteiras diminuíram o tempo de pastejo quando dispunham de pastagem consorciada de azevém e trevo branco (Trifolium repens) comparado às pastagens exclusivas de azevém, possivelmente pelas maiores taxas de digestibilidade da leguminosa, sugerindo que a presença da leguminosa maximizou o aproveitamento de nutrientes.

Algumas espécies e cultivares de leguminosas lançadas nas últimas duas décadas na América do Sul e na América Central são apresentadas na Tabela 1. Ressalta-se que a escolha das espécies e dos cultivares deve ser baseada em condições ambientais, na natureza da exploração e na disponibilidade de recursos naturais para utilização das leguminosas.

No Quadro 2 constam informações sobre as espécies de leguminosas forrageiras de maior importância e disponíveis para uso no Brasil. Além das leguminosas para ambiente tropical, várias espécies para clima subtropical e temperado estão disponíveis para a região Sul do Brasil, e são apresentadas no Quadro 3. Entre as leguminosas que se adaptam bem às condições climáticas subtropicais destacam-se o trevo branco e o cornichão. O trevo branco é uma das leguminosas forrageiras mais importantes e distribuídas ao redor do mundo (Zohary \& Helle; 1984), adaptada a regiões de clima temperado, e apresenta grande importância como espécie forrageira de alta qualidade. 
STIVARI, T.S.S. et al. Leguminosas na alimentação de ovinos: possibilidades de uso e resposta animal. PUBVET, Londrina, V. 5, N. 32, Ed. 179, Art. 1209, 2011.

Tabela 1. Espécies e cultivares de leguminosas forrageiras lançadas nas últimas duas décadas nas Américas do Sul e Central

\begin{tabular}{ll}
\hline Espécie & Ano \\
\hline Arachis pintoi cv. Belmonte & 1999 \\
Arachis pintoi cv. MG 100 & 1994 \\
Arachis pintoi cv. Pico Bonito & 1994 \\
Calopogonium mucunoides cv. Comum & 1999 \\
Centrosema pubescens cv. El Porvenir & 1990 \\
Centrosema pubescens BR1 & 1999 \\
Centrosema pubescens cv. Cardillo & 2000 \\
Dolichos lablab cv. Hilworth & 1999 \\
Dolichos lablab IAC 697 & 1999 \\
Macrotyloma axillare cv. Java & 2004 \\
Stylosanthes macrocephala cv. Campo Grande II & 2000 \\
Stylosanthes capitata cv. Campo Grande I & 2000 \\
Stylosanthes guianensis cv. Bela & 2006 \\
Stylosanthes guianensis cv. Mineirão & 1993 \\
\hline
\end{tabular}

Fonte: adaptado de Paulino et al. (2008) 
STIVARI, T.S.S. et al. Leguminosas na alimentação de ovinos: possibilidades de uso e resposta animal. PUBVET, Londrina, V. 5, N. 32, Ed. 179, Art. 1209, 2011.

Quadro 2. Características agronômicas e adaptativas de algumas espécies e cultivares de leguminosas forrageiras tropicais

\begin{tabular}{|c|c|c|c|c|c|}
\hline Espécie & Cultivar & EF & TMM & PS & VN \\
\hline \multirow{2}{*}{ Arachis pintoi } & Amarillo & \multirow{2}{*}{ Média } & \multirow{2}{*}{ Alta } & Média & \multirow{2}{*}{$\begin{array}{l}\text { Alto, com alta } \\
\text { palatabilidade }\end{array}$} \\
\hline & Belmonte & & & $\begin{array}{c}\text { Nula ou } \\
\text { desprezível }\end{array}$ & \\
\hline $\begin{array}{l}\text { Calopogonium } \\
\text { mucunoides }\end{array}$ & Comum & Baixa & Alta & Alta & Médio \\
\hline Cajanus cajan & Super N & Baixa & Média & Alta & Médio \\
\hline $\begin{array}{c}\text { Leucaena } \\
\text { leucocephala }\end{array}$ & Cunningham & Alta & Média & Alta & $\begin{array}{l}\text { Alto, com alta } \\
\text { palatabilidade }\end{array}$ \\
\hline $\begin{array}{c}\text { Pueraria } \\
\text { phaseoloides }\end{array}$ & Comum & $\begin{array}{l}\text { Média- } \\
\text { Alta }\end{array}$ & Baixa & Alta & Médio \\
\hline $\begin{array}{c}\text { Stylosanthes } \\
\text { guianensis }\end{array}$ & Mineirão & Baixa & Baixa & Baixa & Médio \\
\hline $\begin{array}{l}\text { Stylosanthes } \\
\text { macrocephala }\end{array}$ & Pioneiro & Baixa & Baixa & Alta & Médio \\
\hline $\begin{array}{c}\text { Stylosanthes } \\
\text { spp. }\end{array}$ & Campo Grande & Baixa & Baixa & Alta & Médio \\
\hline $\begin{array}{c}\text { Neonotonia } \\
\text { wighii }\end{array}$ & $\begin{array}{c}\text { Clarence, } \\
\text { Cooper, Tinaroo }\end{array}$ & Alta & Baixa & Média & Alto \\
\hline
\end{tabular}

$\mathrm{EF}=$ exigência de fertilidade do solo; TMM = tolerância ao mau manejo; PS = produção de sementes; $\mathrm{VN}=$ valor nutricional

Fonte: adaptado de Barcellos et al. (2008)

Semelhante ao trevo, o cornichão é uma leguminosa forrageira perene hiberno-primaveril com crescimento rizomatoso. No Brasil, o cultivar comercialmente disponível é o São Gabriel caracterizado pelo rápido crescimento inicial, boa produtividade e elevada qualidade de forragem, longo período vegetativo e boa ressemeadura natural. 
STIVARI, T.S.S. et al. Leguminosas na alimentação de ovinos: possibilidades de uso e resposta animal. PUBVET, Londrina, V. 5, N. 32, Ed. 179, Art. 1209, 2011.

Quadro 3. Alternativas de leguminosas temperadas e suas principais características

\begin{tabular}{|c|c|c|c|c|c|c|}
\hline Espécie & $\begin{array}{c}\text { DS } \\
(\mathrm{kg} / \mathrm{ha})\end{array}$ & $\mathrm{EF}$ & $\mathrm{FP}$ & $\mathrm{EP}$ & $\mathrm{PU}$ & $\mathrm{VN}$ \\
\hline $\begin{array}{c}\text { Trevo Branco } \\
\text { (Trifolium repens) }\end{array}$ & $2-3$ & Alta & Semente & Outono & $\begin{array}{c}\text { Inverno/ } \\
\text { Primavera }\end{array}$ & Alta \\
\hline $\begin{array}{c}\text { Trevo vermelho } \\
\text { (Trifolium pratense L.) }\end{array}$ & $8-10$ & Alta & Semente & Outono & $\begin{array}{c}\text { Inverno/ } \\
\text { Primavera }\end{array}$ & Alta \\
\hline $\begin{array}{c}\text { Trevo vesiculoso } \\
\text { (Trifolium vesiculosum) }\end{array}$ & $8-10$ & $\begin{array}{c}\text { Alta/ } \\
\text { média }\end{array}$ & Semente & Outono & $\begin{array}{c}\text { Inverno/ } \\
\text { Primavera }\end{array}$ & Alta \\
\hline $\begin{array}{c}\text { Cornichão } \\
\text { (Lotus corniculatus L.) }\end{array}$ & $8-10$ & $\begin{array}{c}\text { Alta/ } \\
\text { média }\end{array}$ & Semente & Outono & $\begin{array}{c}\text { Inverno/ } \\
\text { Primavera }\end{array}$ & Alta \\
\hline $\begin{array}{l}\text { DS = densidade de semeadura; EF = exigência de fertilidade do solo; FP = } \\
\text { forma de propagação; EP = época de plantio; PU = período de utilização; VN = } \\
\text { nutricional }\end{array}$ \\
Fonte: adaptado de Monteiro et al. (2007) \\
\hline
\end{tabular}

O Arachis pintoi tem sido amplamente utilizado nas regiões Norte, CentroOeste e Sul do Brasil, sendo uma leguminosa que apresenta características produtivas e qualitativas satisfatórias e boa aceitabilidade pelos animais. As cultivares Amarillo e Belmonte se destacam pelo alto potencial produtivo nas regiões Norte e Centro-Oeste, enquanto a cultivar Alqueire-1 é bem adaptada a região Sul, com alta persistência sob condições de inverno rigoroso (Nascimento, 2006). Recentemente, foram realizados estudos com o objetivo de avaliar as características morfológicas e agronômicas de 12 acessos de $A$. pintoi para utilização na região Sul, com trabalhos realizados no verão (Silva et al., 2010) e no inverno (Fernandes et al., 2010). Nestes estudos, os acessos 6740, FFALM2, FFALM3, FFALM4, W34b1 e W34b2 apresentaram características similares a cultivar Amarillo, com características morfológicas indicando boa qualidade da forragem e a cobertura de solo mostrando bom potencial de competitividade intra e interespecífica no verão, além de alta capacidade de persistência no inverno. Novos estudos deverão ser realizados com estes acessos buscando-se avaliar as respostas produtivas e qualitativas sob condições de pastejo, bem como a aceitabilidade pelos animais. Esses trabalhos são necessários para a validação destes acessos como cultivares, 
STIVARI, T.S.S. et al. Leguminosas na alimentação de ovinos: possibilidades de uso e resposta animal. PUBVET, Londrina, V. 5, N. 32, Ed. 179, Art. 1209, 2011.

sendo passíveis de serem comercializados e utilizados como alternativa para produção de forragem de alta qualidade ao longo ano.

\section{Consorciação Leguminosas x Gramíneas}

Diversas possibilidades de consorciação entre leguminosas e gramíneas poderão existir visando o melhor suprimento de forragem anual, em quantidade e qualidade. $O$ sucesso da consorciação dependente dos fatores ambientais como solo e clima, das características agronômicas das espécies/ cultivares de leguminosas, tais como capacidade de retenção de folhas durante a seca e distribuição da produção de forragem ao longo do ano (Barcellos et al., 2008).

No bioma Cerrado da América do Sul são relatados sucessos de associação entre gramíneas do gênero Brachiaria e as leguminosas Desmodium incanum, Desmodium ovalifolium CIAT 350, Arachis pintoi CIAT 17434 (cv. Maní Forrajero perenne), Centrosema brasilianum, Centrosema macrocarpum, Calopogonium mucunoides, Pueraria phaseoloides. Entre as espécies de Brachiaria, as que apresentam melhores resultados em consorciação com leguminosas são a $B$. brizantha, $B$. humidicola, $B$. dictyoneura e $B$. ruziziensis (Paulino et al. 2008).

Outros exemplos de êxito são reportados pelo mesmo autor com o uso de Stylosanthes guianensis e $A$. pintoi com $B$. brizantha, $B$. decumbens, Andropogon gayanus, Panicum maximum. No caso do Stylosanthes já se tem cultivares tolerantes a Antracnose, dentre os quais figuram o Stylosanthes Campo Grande, que vem sendo utilizada em todo território nacional. De acordo com Yassy \& Campos (2004), a Embrapa Gado de Corte estima que existam mais de 120 mil ha de pastagens consorciadas com leguminosa $S$. macrocephala cv. Campo Grande no Brasil, a maioria no bioma Cerrado.

Alguns fatores que dificultam a definição de estratégias de manejo do pastejo para pastagens mistas de leguminosas e gramíneas são: a) concorrência entre as espécies pelos recursos naturais; b) diferenças em relação ao comportamento das plantas frente ao pastejo; c) diferenças em 
STIVARI, T.S.S. et al. Leguminosas na alimentação de ovinos: possibilidades de uso e resposta animal. PUBVET, Londrina, V. 5, N. 32, Ed. 179, Art. 1209, 2011.

relação à preferência dos animais e, d) as diferenças na reação as variações climáticas (Lascano, 2000).

Na década de 90, Mohr \& Schopfer (1995) descreveram as diferenças entre plantas de ciclos fotossintéticos C3 e C4, enfatizando que a taxa de fotossíntese líquida das plantas C4 é maior que a das plantas C3, o que leva ao crescimento vantajoso das espécies de gramíneas tropicais em relação às leguminosas em geral.

Mesmo em países de clima temperado, com longo histórico de pesquisas com pastagens de leguminosas e gramíneas, há incerteza sobre as estratégias de manejo do pastejo que devem ser adotadas a fim de atingir o equilíbrio em pastagens consorciadas (Hodgson \& Silva, 2000), embora as gramíneas e leguminosas utilizadas nessas regiões apresentem mesmas características fisiológicas de crescimento (espécies de ciclo C3).

Rutter (2006) comparando diversos estudos que descreveram a preferência de ovinos por leguminosas ou gramíneas, relatou preferência de $70 \pm 10 \%$ por trevo. O autor afirmou que a preferência não ocorreu por especificidade à leguminosa ou gramínea estudada, visto que outras forrageiras também foram avaliadas e a preferência por leguminosa manteve-se superior. Wales et al. (2005) afirmaram que a preferência pelo trevo reduz participação na pastagem e que raramente contribui com mais de $20 \%$ da forragem disponível a bovinos leiteiros.

A preferência por leguminosas pode ser afetada pela presença dos taninos (compostos fenólicos provenientes do metabolismo secundário das plantas capazes de formar ligações com vários tipos de proteínas, polissacarídeos e aminoácidos) que em altas concentrações interferem no valor nutritivo da leguminosa. Min et al. (2003) e Waghorn \& McNabb (2003) relataram que concentrações superiores a $7 \%$ na MS podem reduzir o consumo e afetar o ganho de peso para ruminantes. Estes resultados estão associados à capacidade dos taninos condensados em proporcionar adstringência, bem como complexar proteínas, tornando-as indisponíveis à degradação ruminal.

Entretanto, pesquisas indicaram que, com menos de $6 \%$ da MS, os taninos 
STIVARI, T.S.S. et al. Leguminosas na alimentação de ovinos: possibilidades de uso e resposta animal. PUBVET, Londrina, V. 5, N. 32, Ed. 179, Art. 1209, 2011.

proporcionaram efeito inverso através de complexação com compostos nitrogenados, resultando em maior quantidade de proteína não degradada no rúmen (Min et al., 2003; Waghorn \& McNabb, 2003), monitorada através do maior fluxo de aminoácidos essenciais no intestino delgado. Ressalta-se que existem diferenças importantes quanto à concentração de taninos nas plantas e ainda, quanto à estrutura química específica dos taninos, que devem ser consideradas.

Outro efeito benéfico aos pequenos ruminantes referente aos taninos condensados é o seu controle às infecções parasitárias, visto que reduzem o número de nematódeos e diminuem o número de ovos ao prejudicar a fecundidade das fêmeas dos parasitas (Paolini et al., 2005).

Waghorn \& Mcnabb (2003) relataram o uso de plantas leguminosas taniníferas, como o L. pedunculatus cultivar Maku, como ferramenta de controle de parasitas em ovinos na Nova Zelândia. Niezen et al. (1998) contabilizaram redução da infecção parasitária com menor número de ovos por grama de fezes em 40\%, para cordeiros parasitados, alimentando-se da leguminosa sulla (Hedysarum coronarium). Essas respostas podem ser justificadas por dois mecanismos: elevado suprimento de aminoácidos essenciais podem contornar a perda protéica causada pelo parasitismo e devem estimular o sistema imune dos hospedeiros; ainda, os taninos condensados podem reagir diretamente e inativar as larvas durante sua passagem pelo trato gastrointestinal.

Rivas \& Holmann (2000), avaliando leguminosas na produção de bovinos de leite, indicaram que a produção diária de leite aumentou em média 0,5 litros/vaca devido à introdução da leguminosa em pastagens degradadas, e que a utilização de pastagens consorciadas com leguminosas resultou em maior margem de lucro (22\%) do que as tradicionais pastagens em monocultura $(12 \%)$.

No Uruguai, Risso et al. (2002) contabilizaram elevações de 200 para 400 $\mathrm{kg}$ PV/há na produtividade de bovinos mantidos em campos naturais com elevada participação de leguminosas, garantido, ainda, a biodiversidade 
STIVARI, T.S.S. et al. Leguminosas na alimentação de ovinos: possibilidades de uso e resposta animal. PUBVET, Londrina, V. 5, N. 32, Ed. 179, Art. 1209, 2011.

florística da pastagem.

A sobressemeadura de leguminosas forrageiras de inverno, como os trevos, em pastagens formadas por gramíneas perenes de clima tropical, como as espécies do gênero Cynodon spp., é opção a ser considerada para aumentar a produção e a distribuição anual da forragem. Com isso, os "vazios" forrageiros de outono/inverno e inverno/primavera, causados pela diminuição da produtividade das espécies de verão nesses períodos do ano, são reduzidos. Isso possibilita a redução da necessidade de alimentação suplementar com concentrados e a diminuição dos custos oriundos da mesma.

\section{Bancos de Proteína}

Leguminosas sem atributos para conviver diretamente sob pastejo com gramíneas podem ser utilizadas como alimentos suplementares da dieta, chamados no Brasil de "bancos de proteína".

Os bancos de proteínas são áreas separadas da pastagem principal, geralmente formadas por leguminosas em monocultivo, que contribuem na correção da deficiência de proteína e fornecem forragem de melhor qualidade aos animais. É estratégia oportuna para propriedades que não disponibilizam de grandes áreas de pastagem, melhorando o ganho de peso dos animais. Normalmente, deve representar de 10 a $15 \%$ da área da pastagem cultivada com gramíneas (Costa et al., 2008).

Algumas alternativas encontradas na literatura para o manejo dos bancos de proteína são: 1) acesso diário dos animais, por 1 a 2 horas; 2) acesso apenas a cada 2 ou 3 dias, por aproximadamente 1 a 2 horas. Longos intervalos entre pastejos na leguminosa suplementar ou 0 pastejo indiscriminado podem diminuir a eficiência do sistema, prejudicando o desempenho tanto animal quanto forrageiro. Estas áreas podem apresentar duas ou mais subdivisões, permitindo-se fazer rodízio entre elas, visando auxiliar a recuperação da leguminosa, que é normalmente lento, variando de 40 a 60 dias entre as espécies. A forragem em excesso, a partir do manejo do banco de proteína, pode ser conservada através do processo de fenação, ou 
STIVARI, T.S.S. et al. Leguminosas na alimentação de ovinos: possibilidades de uso e resposta animal. PUBVET, Londrina, V. 5, N. 32, Ed. 179, Art. 1209, 2011.

mesmo através de cortes, e fornecida em cocho, no caso de rebanhos menores.

A leguminosa para formação do banco de proteína deve ser adaptada às condições edafoclimáticas locais, tolerante à seca, apresentar elevado teor protéico, ter boa recuperação pós-pastejo e, principalmente, ser consumida pelos animais. A leucena (Leucaena leucocephala (Lam.) de Wit) é a espécie que tem sido mais cultivada e usada como suplemento para caprinos, ovinos e bovinos em todo o Nordeste brasileiro (Cavalcante et al., 2003).

Em estudos realizados por Souza \& Espíndola (2000), a utilização de leucena como banco de proteína para ovinos resultou em aumento da produtividade da pastagem. O estudo ainda considerou a possibilidade de elevar a taxa de lotação de 4 para 6 borregos/ha, sem reduzir o desempenho animal, levando ao aumento da produtividade por área.

Apesar das vantagens no uso de leguminosas como suplemento as gramíneas, Wales et al. (2005) ressaltaram alguns pontos que devem ser considerados quanto ao controle de sua utilização, tais como: a digestão e a fermentação ruminais rápidas podem não ser vantajosas devido à redução de $\mathrm{pH}$ ruminal abaixo de 6,0; menores teores de fibra em detergente neutro, que podem levar à redução no teor de gordura do leite; e concentrações amoniacais maiores que $500 \mathrm{mg} / \mathrm{L}$ que podem superar as exigências dos microorganismos do rúmen.

\section{Creep grazing}

O pastejo restrito de animais lactentes, conhecido como creep grazing, fundamenta-se no acesso exclusivo das crias à pastagem de melhor qualidade, tais como as leguminosas, servindo como fonte privativa de proteína. Dessa forma, a suplementação da cria não substitui o leite materno, mas complementa o mesmo.

O manejo de pastagens em sistemas de creep grazing é facilitado em relação ao manejo de leguminosas consorciadas com gramíneas, pois possibilita melhor controle de plantas daninhas e adubação, com realização de 
STIVARI, T.S.S. et al. Leguminosas na alimentação de ovinos: possibilidades de uso e resposta animal. PUBVET, Londrina, V. 5, N. 32, Ed. 179, Art. 1209, 2011.

práticas agronômicas diferenciadas para cada espécie (Monteiro et al., 2009). Além disso, pesquisas mostram que ovinos apresentam maior preferência por leguminosas (Cosgrove \& Niezen, 2000; Rutter et al., 2002), o que pode contribuir para adoção da técnica de suplementação de cordeiros nesse modelo. A terminação de cordeiros em creep grazing foi considerada por Venning et al. (2004) como forma de melhorar resultados produtivos em pastagens de azevém e trevo. Os autores verificaram que cordeiros pastejando somente azevém e azevém consorciado com trevo obtiveram ganhos médios de 246 e 269 g/dia, respectivamente. Entretanto, quando foi dada a possibilidade de escolha ao cordeiro entre azevém e trevo no creep grazing, o ganho elevou-se para $329 \mathrm{~g} /$ dia. Estudos realizados por Moss et al. (2009) na Nova Zelândia, mostraram que a utilização do creep grazing aumentou significativamente o peso ao desmame dos cordeiros, quando a oferta de leguminosa era elevada.

Para escolha da espécie de leguminosa a ser utilizada no creep grazing deve-se levar em consideração a qualidade nutricional da planta (obrigatoriamente superior à do pasto principal), aceitação por parte dos animais e a adaptação e persistência da espécie na região em que será utilizada.

Conforme ressaltado por Baker (2003), esta ferramenta não deve substituir a boa gestão das pastagens permanentes, mas fazer parte do planejamento forrageiro, sendo necessários pequenos investimentos em mão de obra e insumos para seu estabelecimento. Adicionalmente, o autor descreveu que quanto maior a diferença na quantidade e qualidade da forrageira ofertada no creep grazing em relação ao pasto principal, maiores serão os benefícios da sua utilização.

No Laboratório de Produção e Pesquisa em Ovinos e Caprinos da Universidade Federal do Paraná (LAPOC - UFPR), no ano de 2007, o creep grazing foi avaliado, comparado a outros dois sistemas, com cordeiros terminados ao pé da mãe em pasto sem suplementação e suplementados com creep feeding. A pastagem utilizada foi o Tifton-85 (Cynodon spp.) 
STIVARI, T.S.S. et al. Leguminosas na alimentação de ovinos: possibilidades de uso e resposta animal. PUBVET, Londrina, V. 5, N. 32, Ed. 179, Art. 1209, 2011.

sobressemeada com azevém anual e a leguminosa trevo branco foi utilizada como forrageira suplementar. O ganho médio diário dos cordeiros terminados em creep grazing foi de $294 \mathrm{~g} /$ dia, sendo abatidos aos 89 dias; em creep feeding foi de $324 \mathrm{~g} /$ dia com abate aos 81 dias, sem diferença significativa entre esses sistemas. Da mesma forma, as carcaças dos cordeiros apresentaram-se semelhantes. O trevo exerceu papel nutricional similar ao suplemento concentrado e isto permitiu semelhante resposta produtiva dos animais em creep feeding e creep grazing, superior aos cordeiros não suplementados.

Observou-se predominância do pastejo em trevo branco ( $58 \%$ do tempo em pastejo dos cordeiros) confirmando a preferência pela leguminosa e indicando, assim, a possibilidade de uso do creep grazing nos sistemas de produção na ovinocultura (Piazzetta et al., 2009). No Brasil, isto seria alternativa interessante para a terminação de cordeiros em pastagens.

Apesar dos trabalhos mostrarem resultados promissores para utilização do creep grazing, ainda existem aspectos importantes a serem estudados. Monteiro et al. (2009) destacaram a necessidade de pesquisas sobre dimensionamento das áreas e posicionamento ideal dos piquetes acessórios em relação ao principal, visando pastejo uniforme e redução da interferência da presença materna no lado de fora. Da mesma forma, seria interessante conhecer quais os níveis mais apropriados de oferta de forragem para suplementação dos cordeiros, bem como o uso de diferentes espécies e combinações adequadas para diferentes regiões e épocas do ano.

\section{CONSIDERAÇÕES FINAIS}

As leguminosas forrageiras podem trazer maior disponibilidade de $\mathrm{N}$ ao solo, melhoria da qualidade da forragem e maiores ganhos individuais e por área, além de garantir diversidade florística e favorecer, dessa forma, a sustentabilidade ambiental e econômica dos sistemas pecuários. 
STIVARI, T.S.S. et al. Leguminosas na alimentação de ovinos: possibilidades de uso e resposta animal. PUBVET, Londrina, V. 5, N. 32, Ed. 179, Art. 1209, 2011.

Diversas são as espécies e cultivares de leguminosas disponíveis comercialmente, porém sua implementação nos sistemas varia de acordo com as condições edafoclimáticas, persistência das mesmas e forma de utilização. Sua utilização na forma de consorciação com gramíneas, banco de proteínas e creep grazing tem apresentado bons resultados para ovinos e são estratégias promissoras.

\section{REFERÊNCIAS}

AGROANALYSIS: A revista de agronegócios da FGV - globalização da pecuária. Rio de Janeiro: Fundação Getúlio Vargas, v.28, n.11, p.19-40, 2008.

ALMEIDA, R.G.; NASCIMENTO, JR., D.; EUCLIDES, V.P.B. et al. Produção animal em pastos consorciados sob três taxas de lotação no Cerrado. Revista Brasileira de Zootecnia, v.32, n.2, p.852-857, 2002.

BAKER, B. Forage management: creep grazing. Extension Service: West Virgina University, 2003.

BARCELLOS, A.O.; RAMOS, A.K.B.; VILELA, L. et al. Sustentabilidade da produção animal baseada em pastagens consorciadas e no emprego de leguminosas exclusivas, na forma de banco de proteína, nos trópicos brasileiros. Revista Brasileira de Zootecnia, v.37, n.[S.I.], 2008.

BOGGIANO, P.; FORMOSO, D.; ZANONIANI, R. Alternativas para incrementar la productividad de las pasturas naturales del Uruguay. In: BRANCO, A.F. et al. (Org.) SUSTENTABILIDADE EM SISTEMAS PECUÁRIOS - WORKSHOP INTERNACIONAL. Maringá: Massoni, 2006. Anais... Sustentabilidade em Sistemas Pecuários, Maringá, 2006, p.14-26.

CARVALHO FILHO, O.M.; DRUMOND, M.A.; LANGUIDEY, P.H. Gliricidia sepium Leguminosa promissora para regiões semi-áridas. Petrolina-PE: EMBRAPA Semi-Árido. Circular Técnica, n.35, 2007. 16p.

CARVALHO, G.G.P.; PIRES, A.J.V. Leguminosas tropicais herbáceas em associação com pastagens. Archivos de Zootecnia, v.57, n.1, p.103-113, 2008.

CAVALCANTE, A.C.R.; SOUSA, F.B.; CÂNDIDO, M.J.D. Estratégia de manejo de pastagens cultivadas no semi-árido. Sobral-CE: EMBRAPA Caprinos. Documentos, n.45, 2003. 28p.

COSGROVE, G.P.; NIEZEN, J.H. Intake and selection for white clover by grazing lambs in response to gastrointestinal parasitism. Applied Animal Behavior Science, v.66, p.71-85, 2000.

COSTA, N.L.; BENDAHAN, A.B.; GIANLUPPI, V. et al. Formação e manejo de bancos-deproteína em Roraima. Boa Vista-RR: EMBRAPA Roraima. Comunicado Técnico, n.12. 2008. $5 p$.

FAO - Food and Agricultural Organization of United Nations. Country Briefs - Brazil. 26/05/2010. Acesso em 31/05/2010. Online. Disponível em: <http://www.fao.org/countries/55528/en/bra/>.

FAOSTAT - Food and Agricultural Organization of United Nations. 2008. Acesso em 31/05/2010. Online. Disponível em: <http://faostat.fao.org>. 
FERNANDES, S.R.; SILVA, C.J.A.; MONTEIRO, A.L.G. et al. Comparação de acessos de Amendoim Forrageiro (Arachis pintoi, Krap. \& Greg.) na Região Sul do Brasil: características morfo-agronômicas durante o inverno. In: REUNIÃO ANUAL DA SOCIEDADE BRASILEIRA DE ZOOTECNIA, 47., 2010 Anais... Salvador: Sociedade Brasileira de Zootecnia, 2010. (CDROM).

GONÇALVES, C.A.; COSTA, N.L. Avaliação agronômica de Brachiaria humidicola em consorciação com leguminosas forrageiras tropicais em Rondônia. Revista Brasileira de Zootecnia, v.23, n.5, p.699-708, 1994.

HACKER, B. Priorities and activities of the Australian Tropical Forages Genetic Resource Centre. Tropical Grasslands, v.31, p.243-250, 1997.

HODGSON, J.; SILVA, S.C. Sustainability of grazing systems: goals, concepts and methods. In: LEMAIRE, G.; HODGSON, J.; MORAES, A. et al. (Ed.) Grassland Ecophysiology and Grazing Ecology. Wallingford: $C A B$ International, 2000. p.1-13.

JINGURA, R.M.; SIBANDA, S.; HAMUDIKUWANDA, H. Yield and nutritive value of tropical forage legumes grown in semi-arid parts of Zimbabwe. Tropical Grassland, v.35, p.168-174, 2001.

LASCANO, C.E. Selective grazing on grass-legume mixtures in tropical pastures. In: LEMAIRE, G. et al. (Ed.) Grassland Ecophysiology and Grazing Ecology. Wallingford: $C A B$ International, 2000. p.249-263.

MIN, B.R.; BARRY, T.N.; ATTWOOD, G.T. et al. The effect of condensed tannins on the nutrition and health of ruminants fed fresh temperate forages: a review. Animal Feed Science and Technology, v.106, p.3-19, 2003.

MOHR, H.; SCHOPFER, P. Plant Physiology. Ed. Springer, 1995. 629p.

MONTEIRO, A.L.G.; POLI, C.H.E.C.; MORAES, A. et al. Produção de ovinos em pastagens. In: SIMPÓSIO SOBRE MANEJO DA PASTAGEM, 24., 2007, Piracicaba. Anais... Piracicaba: FEALQ, 2007. p.377-458.

MONTEIRO, A.L.G.; PIAZZETTA, H.V.L.; PAULA, E.F.E. et al. Aspectos da utilização de leguminosas e suplementação concentrada aos ovinos. Farmpoint Ovinos e Caprinos, Rede Agripoint, 2009.

MONTENEGRO, J.; ABARCA, S. Fijación de carbon, emisión de metano y óxido nitroso em sistemas de produción bovina em Costa Rica. En. Intensificación de la ganaderia em Centroamérica - benefícios econômicos y ambientales. CATIE-FAO-SIDE. Editado por Nuetra Terra, 2000. 334p.

MOSS, R.A.; DYNES, R.A.; GOULTER, C.L. et al. Forward creep grazing of lambs to increase live weight gain and post-weaning resistance to endoparasites. New Zealand Journal of Agricultural Research, v.52. p.399-406, 2009.

NASCIMENTO, I.S. O cultivo do amendoim forrageiro. Revista Brasileira de Agrociência, v.12, n.4, p.387-393, 2006.

NIEZEN, J.H.; ROBERTSON, H.A.; WAGHORN, G.C. et al. Production, faecal egg count and worm burdens of ewe lambs which grazed six contrasting forages. Veterinary Parasitology, v.80, n.1, p.15-27, 1998.

PAOLINI, V.; DE LA FARGE, F.; PREVOT, F. et al. Effects of the repeated distribution of sainfoin hay on the resistance and the resilience of goats naturally infected with gastrointestinal nematodes. Veterinary Parasitology, v.127, 277-283, 2005.

PAULINO, V.P.; LUCENA, M.A.C.; GERDES, L. et al. In: ENCONTRO TÉCNICO SOBRE LEGUMINOSAS FORRAGEIRAS - DESAFIOS E PERSPECTIVAS, 2., 2008. Anais... Instituto de Zootecnia, 2008. 168p. 
PIAZZETTA, H.V.L.; MONTEIRO, A.L.G.; RIBEIRO, T.M.D. et al. Comportamento ingestivo de cordeiros em terminação a pasto. Acta Scientiarum, v.31, n.3, p.227-234, 2009.

POLI, C.H.E.C.; JOCHIMS, F.; MONTEIRO, A.L.G. et al. Ovinocultura no bioma Pampa. In: PILLAR, V.P. et al. (Eds.) Campos Sulinos - Conservação e Uso Sustentável da Biodiversidade. Brasília, 2009. Cap.17, p.229-236.

RISSO, D.F.; MONTOSSI, F.; BERRETTA, E.J. et al. Utilización de mejoramientos de campo en pastoreo mixto para engorde de novillos y corderos en la región de Cristalino: comportamiento de novillos en engorde y persistencia productiva de las pasturas. In: RISSO, D.F.; MONTOSSI, F. (Eds.) Fertilización, producción de carne de calidad y persistencia productiva. INIA Tacuarembó, Serie Técnica n.129, Montevideo: Hemisferio Sur, 2002. p.39-58.

RIVAS, L; HOLMANN, F. Early adoption of Arachis pintoi in the tropics: the case of dualpurpose livestock systems in Caquetá, Colombia. Journal of Livestock Research for Rural Development, v.12, n.3, 2000.

RUTTER, S.M. Diet preference for grass and legumes in free-ranging domestic sheep and cattle: current theory and future application. Applied Animal Behavior Science, v.97, p.1735, 2006.

RUTTER, S.M.; ORR, R.J.; PENNING, P.P. et al. Ingestive behaviour of heifers grazing monocultures of ryegrass or white clover. Applied Animal Behavior Science, v.76, p.1-9, 2002.

RUTTER, S.M.; YOUNG, K.; CHAMPION, R.A. et al. Strip grazing separate white clover and ryegrass monocultures increases daily intake and milk yield in dairy cows. Tropical and Subtropical Agronomy, v.3, p.461-465, 2003.

SANTOS, I.P.A., PINTO, J.C.; SIQUEIRA, J.O. et al. Influência do fósforo, micorriza e nitrogênio no conteúdo de minerais de Brachiaria brizanta e Arachis pintoi consorciados. Revista Brasileira de Zootecnia, v.31, n.2, p.605-616, 2002.

SCOLLAN, N.D.; DEWHURST, R.J.; MOLONEY, A.P. et al. Improving the quality of products from grassland. In: INTERNATIONAL GRASSLAND CONGRESS, 23., 2005, Dublin. Proceedings... Dublin, 2005. p.41-56.

SILVA, C.J.A.; FERNANDES, S.R.; MONTEIRO, A.L.G. et al. Comparação de acessos de Amendoim Forrageiro (Arachis pintoi, Krap. \& Greg.) na Região Sul do Brasil: características morfo-agronômicas durante o verão. In: REUNIÃO ANUAL DA SOCIEDADE BRASILEIRA DE ZOOTECNIA, 47., 2010, Anais... Salvador: Sociedade Brasileira de Zootecnia, 2010. (CDROM).

SOUZA, A.A.; ESPINDOLA, G.B. Bancos de proteína de leucena e de guandu para suplementação de ovinos mantidos em pastagens de capim-buffel. Revista Brasileira de Zootecnia, v.29, n.2, p.373-381, 2000.

THOMAS, R.J. Role of legumes in providing $\mathrm{N}$ for sustainable tropical pasture systems. Plant and Soil, v.174, n.1, p.103-118, 1995.

VENNING, K.J.; THOMPSON, A.N.; CHAPMAN, D.F. et al. Ewe and lamb growth from adjacent monocultures of grass and clover. Animal Production in Australia, v.25, p.336, 2004.

WAGHORN, G.C.; McNABB, W.C. Consequences of plant phenolic compounds for productivity and health of ruminants with gastrointestinal nematodes. Veterinary Parasitology, v.127, 277-283, 2003.

WALES W.J., STOCKDALE C.R., DOYLE P.T. Plant and sward characteristics to achieve high intake in ruminants. In: Murphy J.J. (Ed.) Utilisation of Grazed Grass in Temperate Animal Systems. Proceedings of a Satellite Workshop of the International Grassland Congress, 20., 2005. Wageningen, The Netherlands: Wageningen Academic Publishers, 2005. p.37-47 
YASSY, F.; CAMPOS, J.M.N. Leguminosa casa bem com capim. Revista DBo Rural, v.23, n.281, p.60-70, 2004.

ZOHARY, M.; HELLER, D. The genus Trifolium. Jerusalem: The Israel Academy of Sciences and Humanities, 1984. 606p. 